edge of a problem of much biological interest. Mrs. Dorsey summarizes her observations in a special discussion of aleurodid develop. ment. A list with references, together with an analytical table, of all the North American species of the family are given. The paper is unusually well supplied with drawings, in which work Mrs. Dorsey has been aided by Mary Wellman, scientific artist.

Vernon L. Kellogg.

\title{
THE PUPA OF MERMIRIA TEXANA BRUNER.
}

BY T. D. A. COECKRELl, EAST LAS VEgAS, N. MEX.

Orthopterists have not usually paid much attention to the pupae of grasshoppers; partly, no doubt, because they rarely offer any remarkable characters, and partly because they often shrivel and lose their natural colors, when pinned in the cabinet. The pupa of Mermiria texana, now described, is a very striking and beautiful creature when alive, and it seems well worth while to present an account of it.

9. Length $34-36 \mathrm{~mm}$., antennae $10 \frac{1}{2}$ $\mathrm{mm}$., dorsal surface of head $5 \frac{1}{2} \mathrm{~mm}$., pronotum $5 \frac{1}{2} \mathrm{~mm}$., tegmina $8 \mathrm{~mm}$., end of tegmina to tip of abdomen $16-18$ $\mathrm{mm}$., femur $\mathrm{r} 6 \mathrm{~mm}$., tibia $\mathrm{r}_{5} \mathrm{~mm}$., breadth of thorax $4 \mathrm{~mm}$. 2 I spines on outer margin of hind tibia. Brown of various shades, with pure white longitudinal stripes; top of head with a broad median longitudinal pale sepia band, narrowly edged with darker; on each side of this a broad pale apricot or reddish-ocherous band, clouded with pale gray, and externally bordered with white, the white border running through the upper edge of the eye; next to this a broad dark sepia band, also bordered below with white; then a dilute gray band, marbled with lighter veins and at its lower part spotted with darker; this lower spotted part bordered below with white; running from below the eye, bordering on the lateral carinae of the face, is a pale reddish-ochreous band. Eye gray, its upper part spotted, its lower part striped with grayish-white. Face gray mottled with blackish, the median carinae pale. Antennae a warm brown, distinctly triquetrous towards base, not nearly so broad as the shorter diameter of the eye. The prothorax continues the longitudinal markings of the head, but the median zone, is mottled with dark gray, and its ground-color is inclined to purple, with the median carina, which is very distinct, is indicated by a pale line. The subdorsal dark band passes backwards along the thorax and abdomen, crossing the tegmina, which thus have their lower half dark and the upper a light warm reddishochreous. On the sides of the thorax the dark band is broadly bordered below by white; but on the abdomen it is narrow, and is bordered above by white. 
The abdomen is strongly keeled dorsally, the region of the keel being purplish, somewhat mottled, and changing into light ochreous above the white (interrupted) subdorsal lines. Sides of abdomen mottled with purplish and dull white. Femora with an ochreous line above, and a white line at the sides marking the ridges. Tibiae pale purplish, mottled with pink at sides, with a dark gray stripe beneath. Spines rosy, tipped with black.

․ Green form. Similar but apple green in place of brown, and hardly any mottling; median zone of head and prothorax a dull emerald green, not mottled. Lateral band a deep olive-green, the white edging very distinct and beautiful. Ground-color of tibiae pale bluish.

Hab. Las Vegas Hot Springs, N. M., July I I, I899. (W. Porter and S. Mize.)

I give also a brief description of the adult from the same place:

Notes.-Carabus nemoralis Müll. is taken not uncommonly at Cambridge, Mass. Other North American records are Hudson's Bay, St. John, N. B., and Maine.

In Caterpillars and their moths (New York. The Century Company, 1902), Miss Eliot and Miss Soule record their long and varied experiences in the rearing of moths. Chapters one to six, pages $3-66$, deal with appliances, structure, habits, methods of care, preservation, note-taking, etc.; and chapters seven to seventeen, pages 69-299, are devoted to more or less detailed life histories of a number of common moths, chiefly sphingine and bombycine.

The text, with the exception of the part re-
․ Like the pupa, but colors grayer, not so reddish; hind tibiae coral red. Tegmina blackish with a yellowish-white subcostal stripe and another stripe in the median field, beginning abruptly just below the middle of the tegmen; a longitudinal ochreous stripe along the lower margin continuous and concolorous with the subdorsal stripes of the thorax. Wings tinged with yellowish, apical third dusky. I7 spines on outer margin of hind tibia. Measurements in mm.: antenna, 16 , vertex $5 \frac{1}{2}$, pronotum $6 \frac{1}{2}$, tegmina 30 , end of pronotum to tip of abdomen $29 \frac{1}{2}$, hind femur $21 \frac{1}{2}$, hind tibia

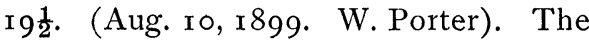
adult was kindly determined by $\mathrm{Mr}$. Scudder. Brunner found the species only among Agave; it did not occur near or upon Agave at Las Vegas Hot Springs. The tegmina in our form are appreciably shorter than in Bruner's types.

lating to structure, is quite satisfactory so far as facts are concerned, but from a literary standpoint it lacks simplicity. The colloquialness of the style and the frequent use of "One of Us," six times on a single page, is especially displeasing.

The illustrations are from photographs by Miss Edith Eliot and show the caterpillars and spread moths of most of the species treated. Those of the caterpillars are uniformly good, while those of the moths are more uneven as properly spread specimens were not always selected for illustration. The index even as a list of names is inadequate and the rendering of some of the scientific names shows careless proof reading. 

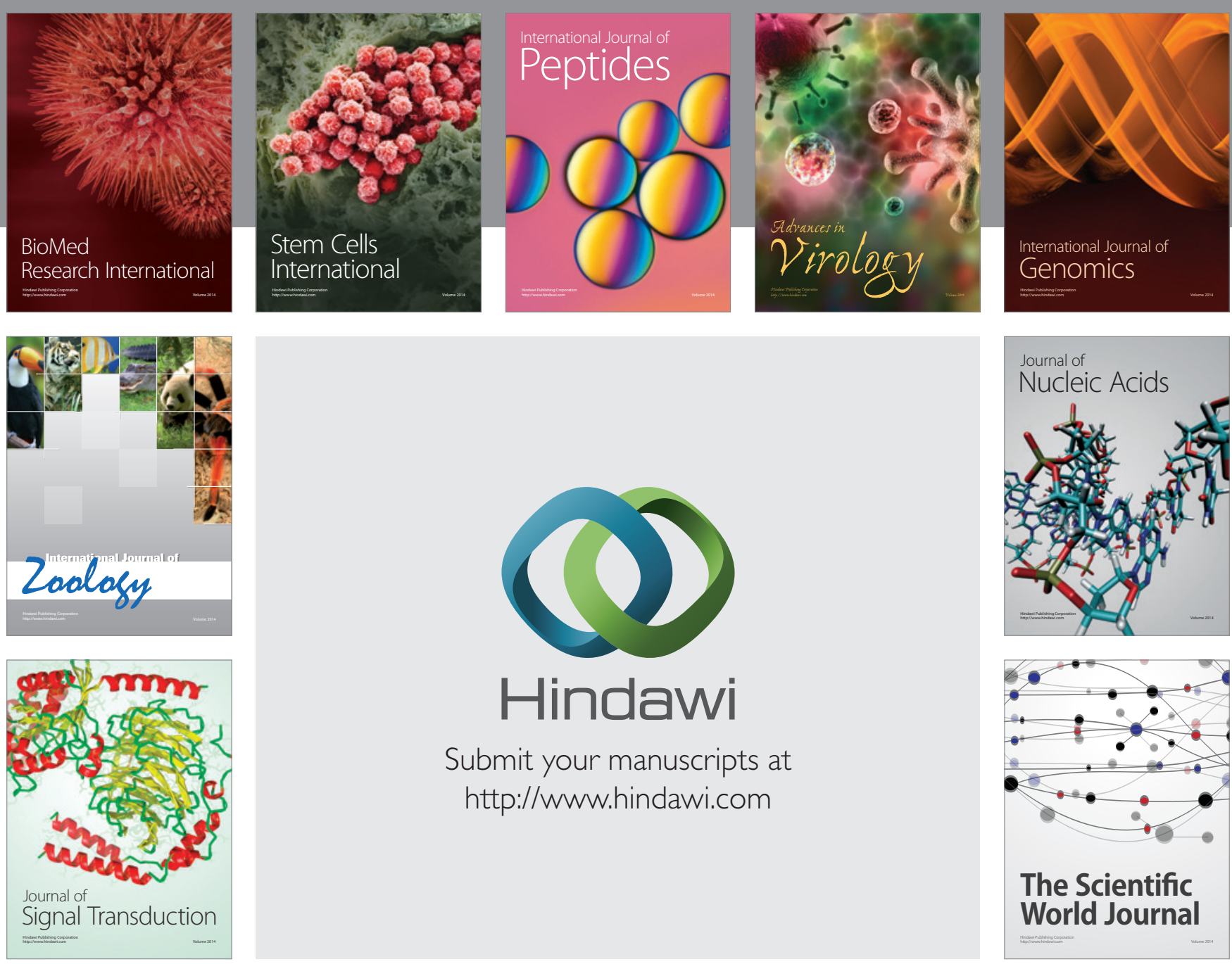

Submit your manuscripts at

http://www.hindawi.com
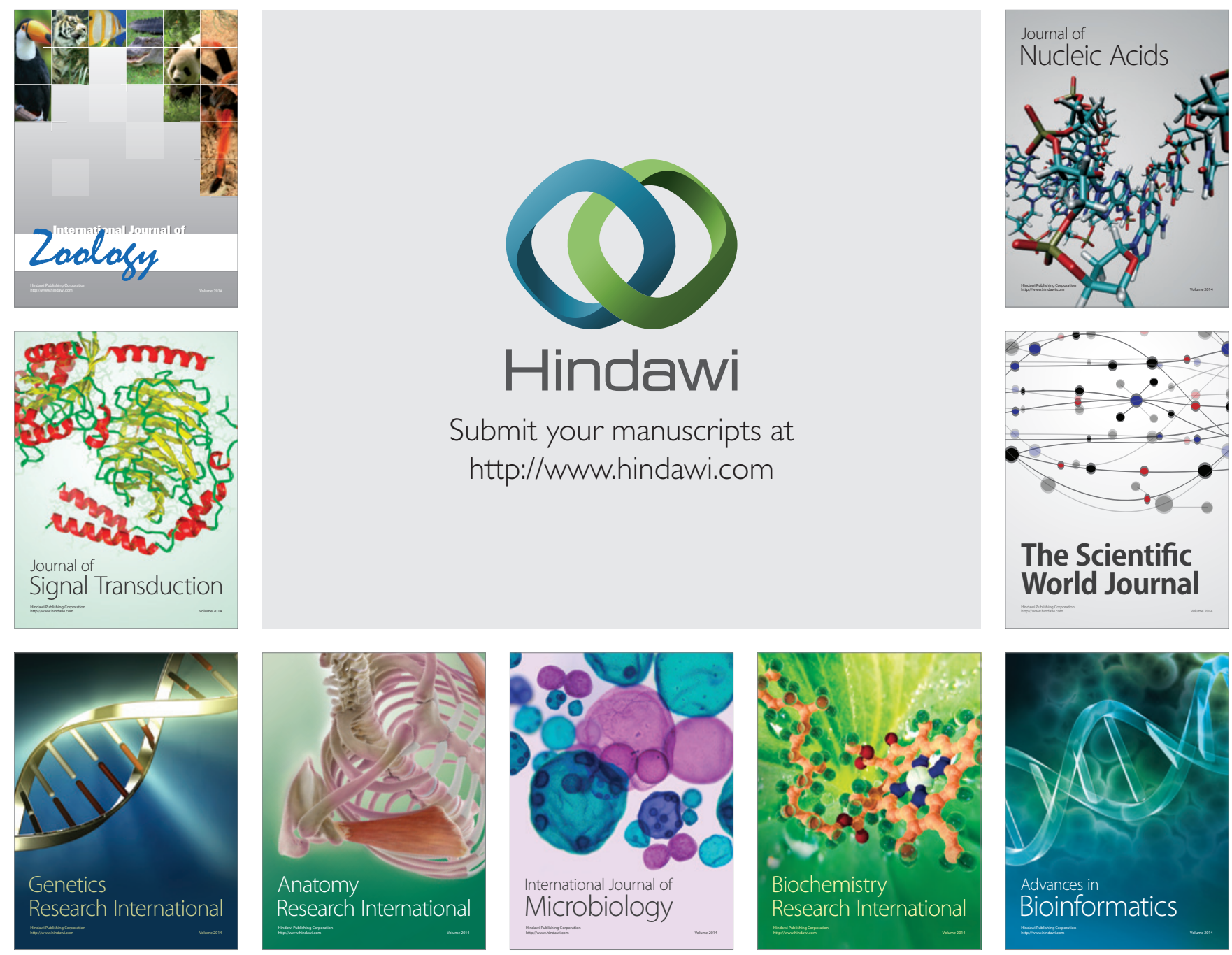

The Scientific World Journal
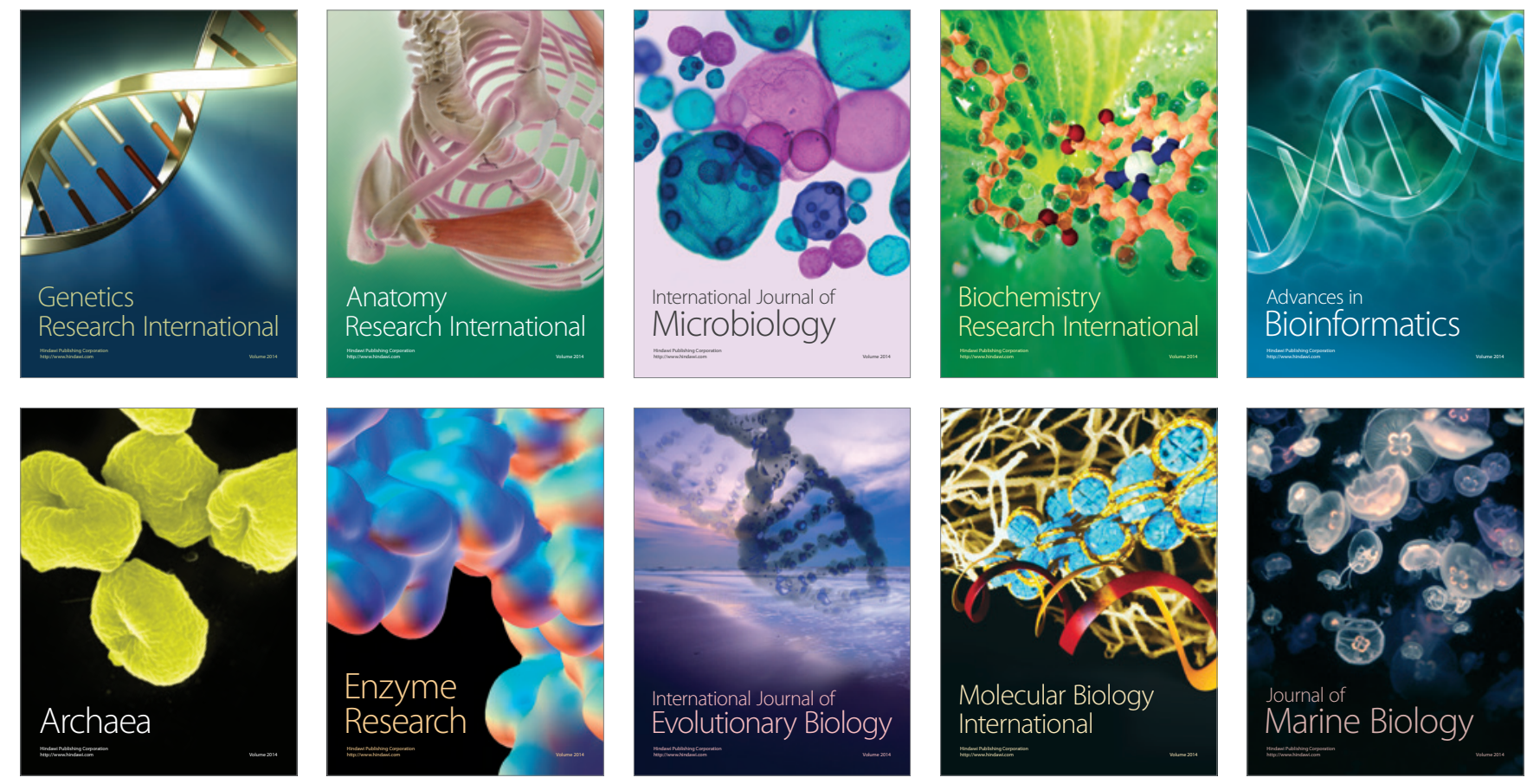